\title{
La construcción de la memoria de un lugar en la prensa. Urabá en la Revista Semana $\underline{(1980-2002)^{1}}$
}

\author{
Julián Penagos Carreño ${ }^{2}$
}

Recibido: 16 de diciembre de 2010

Aprobado: 3 de febrero de 2011

\begin{abstract}
Resumen
El documento parte del concepto teórico de la prensa como fuente y referente de construcción significativa de memoria de un lugar, en este caso Urabá, Colombia. Hace el análisis de treinta artículos de la Revista Semana publicados entre los años 1980 y 2002 y los compara con algunas obras historiográficas que abordan el tema de Urabá. Se concluye que la Revista Semana elabora una narración centrada en el conflicto armado construida de manera reduccionista, sin contexto y simplista del lugar y que esto afecta la construcción de la memoria y la imagen de Urabá, haciéndola ver como una zona tórrida, violenta y sin esperanza.
\end{abstract}

Palabras clave: Urabá, representación, Estado, sociedad, conflicto.

Este artículo de investigación es un documento de trabajo que hace parte del proyecto "Las Representaciones del Conflicto Colombiano en la prensa" para optar por el título de Maestría en Historia de la Universidad de los Andes.

2 Profesor Asistente de la Facultad de Comunicación de la Universidad de la Sabana. Comunicador Social con Maestría en Historia de la Universidad de los Andes. Correo electrónico: julianpenagos78@hotmail.com 


\title{
Memory Construction of a Place in the Press. Urabá in Semana Magazine. (1980-2002).
}

\begin{abstract}
This article starts with a theoretical concept of the press as a source and a reference of meaningful memory construction of a place (Urabá, Colombia in this case). The article makes an analysis of thirty articles from Semana Magazine, published between 1980 and 2002 and compares them with some historiographic works with respect to Urabá. The article concludes that Semana Magazine makes a narration focused on the armed conflict and constructed in a reductionist and simplistic way with no context, and that this affects Urabá memory construction and image, showing this place as a torrid, violent, and hopeless region.
\end{abstract}

Key words: Urabá, representation, State, society, conflict. 


\section{Introducción}

Según Jacques Le Goff la memoria colectiva y su "forma científica", la historia, están aplicadas en dos tipos de materiales: los documentos y los monumentos. (Le Goff, 1991, p.227). Para el historiador francés es claro que existe una revolución documental en la labor histórica, y que por lo tanto se da una ampliación tanto cualitativa como cuantitativa del documento, ya que "El interés de la memoria colectiva y de la historia ya no se cristalizan exclusivamente en los grandes hombres, los acontecimientos, la historia que transcurre de prisa, la historia política, diplomática, militar. Esta ahora se ocupa de todos los hombres, comporta una nueva jerarquía más o menos supuesta de los documentos..." (Le Goff, 1991, p. 232). En este sentido, son necesarios nuevos tipos de documentos que den cuenta de esos datos que "lleva a la serie y a una historia discontinua" del pasado. (Le Goff, 1991, p. 233) La prensa se ha convertido en una de esas opciones documentales, cada vez más comunes, para ser fuentes sobre hechos históricos debido a que primero que nada, los periódicos tienen información que está "fijada materialmente sobre un soporte y que puede ser utilizada para la consulta, estudio o trabajo como herramienta indispensable para transmitir conocimientos, ideas y dar testimonios de los hechos" (Rodríguez, 1999, p. 33).

Y segundo, según la historiadora española María Luz Arroyo Vásquez (2004) en su estudio sobre la percepción española del modelo de elecciones norteamericano, "las fuentes hemerográficas ofrecen un ámbito para la reflexión, tienen un carácter de testimonio diario, coetáneo de la vida política, socio-económica, y cultural, e indiscutiblemente, poseen un valor intrínseco como fuente primaria" (p. 9).

Los periódicos se constituyen entonces como el depósito de los hechos que forjan la memoria histórica de los individuos de un país o pueblo; por medio de ellos se transmiten y se conservan los acontecimientos de las sociedades, por las páginas de un diario circula el sentido de un tiempo pasado y el espíritu del presente. Pero, como afirma Arroyo, también tienen sus limitaciones, ya que la prensa es un vehículo ideológico cuyo discurso tiene una intención política, religiosa o económica. Es así como LeGoff (1991), citando a Michel Foucault, plantea el problema del "proceso del documento" (p. 236) en cuanto que estos son el producto de una sociedad que los selecciona y los define. Así las cosas, la labor del historiador es la del exhaustivo cotejar de las fuentes para comprobar la fiabilidad de las mismas.

Este ensayo pretende responder a las preguntas sobre ¿Qué memoria se construye sobre un acontecimiento en la prensa? ¿Qué sujetos se visibilizan? ¿De qué forma? Procura hacer un análisis en el que se intente cotejar lo que se construye en la prensa sobre un proceso histórico y algunas fuentes historiográficas secundarias. Se han escogido treinta artículos de la Revista Semana sobre el Urabá Antioqueño entre 1980 y 2002. La tesis principal es que Urabá es narrado en la Revista Semana desde el conflicto con lo cual se crea una memoria estereotípica de la región hasta estigmatizarla. En este sentido, la memoria construida a partir de la prensa corresponde a una visión reduccionista del lugar.

El texto está dividido en cinco partes: en la primera se presenta una descripción geográfica del Urabá antioqueño para contextualizar la discusión dentro un sitio físico real; la segunda explica las construcciones efectuadas en la revista en los años ochenta que se basan en la colonización; la tercera describe el lugar a partir de la visibilidad de los esfuerzos del Estado por influir en la región; la cuarta delinea los enfrentamientos entre los grupos armados ilegales y legales, y la quinta, presenta una conclusión en la que se explica qué tipo de memoria se puede construir sobre un sitio o situación tomando la prensa como referencia.

\section{El valor geoestratégico de Urabá. Falencia en las representaciones de la Revista Semana}

La gran falencia de las representaciones de Urabá en los artículos de la Revista Semana es el de la explicación del valor geográfico, estratégico y económico que representa la zona para la inser- 

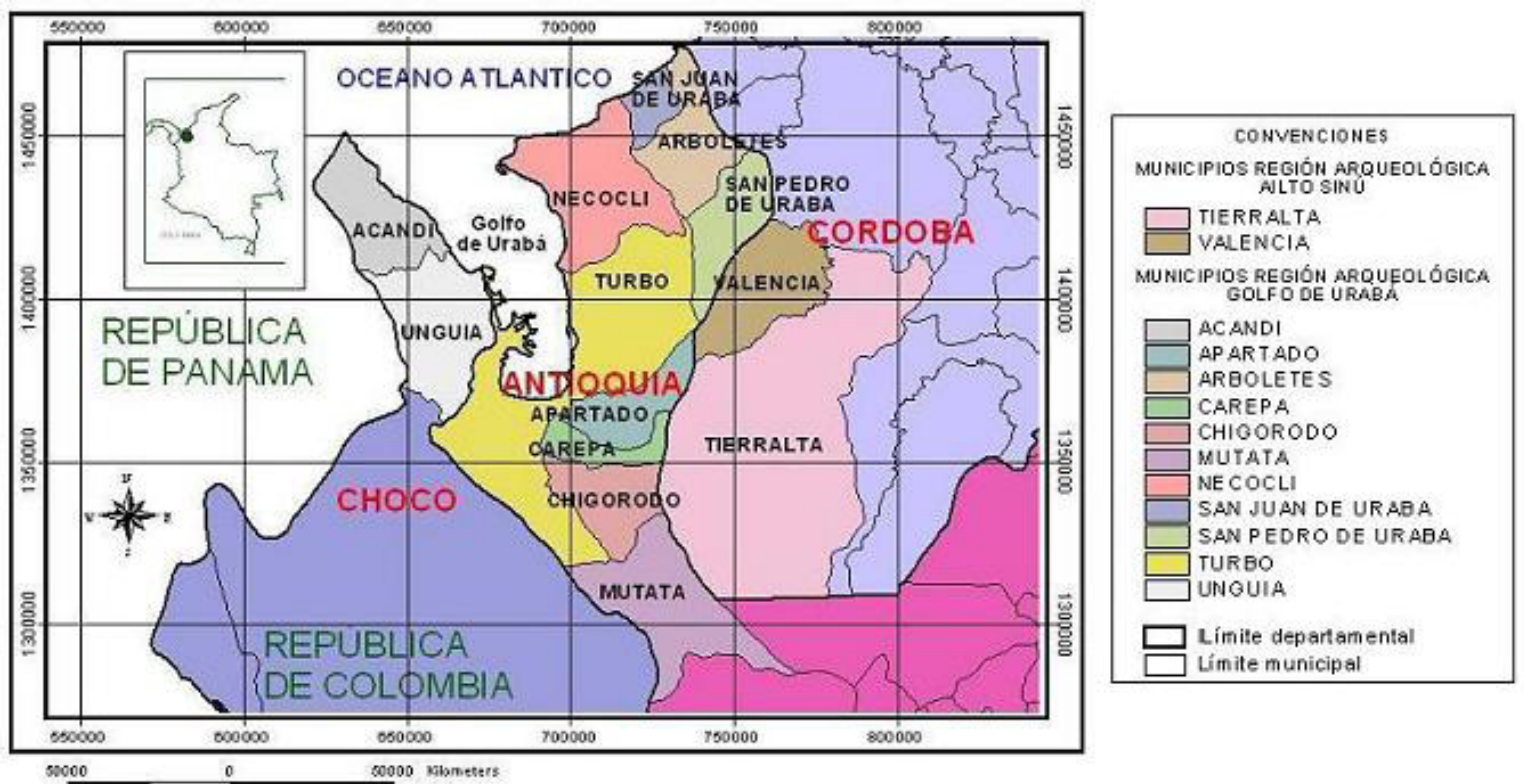

Fuente: ICANH www.icanh.gov.co

Gráfica 1. Descripción geográfica de Urabá

ción de las distintas violencias, es decir ¿por qué se lucha en Urabá? Por eso es necesario hacer una descripción del Urabá Antioqueño, para tratar de entrever aquellos aspectos que la Revista Semana no dice o que simplemente nombra de manera superficial.

La región se encuentra ubicada en la parte izquierda de la cordillera occidental en la serranía de Abibe y el valle del río Atrato. Urabá tiene una extensión de $11.671 \mathrm{~km} 2$ con una densidad de población de 36,4 en 1998 y de 39,71 en 2002. Según el informe de la Cámara de Comercio de Urabá para el 2005 la población estaba en los 500 mil habitantes lo que demuestra un aumento en 300 mil desde los años 90, cuando la población era de 202.442 habitantes (García, 1996, pág. 32). Lo componen 11 municipios: Arboletes, Necoclí, San Juan de Urabá, San Pedro de Urabá, Apartadó,

Tabla 1. Distribución espacial de la población por zonas

Población (2005)

\begin{tabular}{|c|c|c|c|c|c|}
\hline Localización & Municipio & Área $(\mathrm{Km} 2)$ & Urbana & Rural & Total \\
\hline ZONA NORTE & Arboletes & 710 & 8.325 & 13.454 & 21.779 \\
\hline & $\begin{array}{c}\text { San Juan de } \\
\text { Urabá }\end{array}$ & 239 & 10.840 & 12.616 & 23.456 \\
\cline { 2 - 6 } & Necoclí & 1.361 & 10.836 & 31.802 & 42.638 \\
\cline { 2 - 6 } & $\begin{array}{c}\text { San Pedro de } \\
\text { Urabá }\end{array}$ & 476 & 11.104 & 23.795 & 34.899 \\
\hline ZONA CENTRO & Apartadó & 600 & 85.948 & 17.222 & 103.170 \\
\hline & Turbo & 3.055 & 50.549 & 75.476 & 126.025 \\
\hline & Carepa & 380 & 20.653 & 25.739 & 46.392 \\
\hline ZONA SUR & Chigorodó & 608 & 48.530 & 14.462 & 62.992 \\
\hline & Mutatá & 1106 & 4.814 & 11.912 & 16.726 \\
\hline
\end{tabular}

*Fuente: Departamento Administrativo de Planeación. 
Carepa, Chigorodó, Turbo, Murindó, Mutatá y Vigía del Fuerte. (Ver gráfica 1)

La concentración de población se da en la parte central de la región donde vive el $70 \%$ de los pobladores. Esta cifra es importante porque anuncia un desequilibrio entre las zonas rurales con condiciones de vida inferiores a las de las zonas urbanizadas (ver tabla 1). Esto, como se verá más adelante, tiene que ver con los procesos de colonización descontrolada, con la industrialización diferenciada y las dinámicas de los actores de la guerra.

Dirección Sistemas de Indicadores Anuario estadístico 2004 En Informe de Cámara de comercio.

La división en estas zonas se convierte en una fragmentación en el desarrollo social, económico y político debido a la dinámica del conflicto. Por ejemplo, en cuanto al desarrollo social "Es claro que para la zona norte los crecimientos son tanto urbanos como rurales (Arboletes, Necoclí Turbo), mientras que para la zona centro, nos encontramos con crecimientos rurales acompañados de fuertes crecimientos de los centros urbanos (Carepa, Chigorodó)". (Comercio, 2005).

Con respecto a la actividad productiva, el Urabá Antioqueño es utilizado para actividades de ganadería y agricultura. Pero se encuentra fragmentado en el uso y las utilidades productivas de tal forma que puede ser dividido así: subregión del norte donde predominan las actividades de ganadería extensiva; la subzona centro es caracterizada como agroindustrial donde se concentra el cultivo del banano y las empresas que explotan este recurso. La subregión del sur caracterizada como la más pobre de las tres, sus terrenos se consideran espacios baldíos para la colonización.

A esta descripción de territorio se le suma una división realizada por Fernán González, Ingrid Bolívar y Teófilo Vásquez (2002, p. 121), a partir de la clasificación realizada por William Ramírez Tobón (1997) en el Informe de verificación de los actores violentos en Urabá, a la cual los teóricos le sumaron los datos de su investigación sobre la dinámica del conflicto. Para los años noventa y principios del 2000, la zona norte es de control paramilitar con predominio del latifundio y centro en San
Pedro de Urabá; en algunos sitios de esta zona se encuentran aún algunas formas de colonización campesina y de la guerrilla. La subregión centro es el eje de la disputa por el territorio entre los actores armados. La subregión del sur hace las veces de retaguardia y refugio de la guerrilla (FARC) debido a su característica selvática.

De este panorama se pueden deducir tres disputas debido al valor estratégico de la zona: a. La disputa por el territorio entre los grupos armados legales e ilegales (ejército, guerrilla, paramilitares) b. por el control de la industria del banano y por los terrenos baldíos para sembrar droga. Y c. La disputa por la zona de la carretera (Parsons, 1996) que comunica Antioquia con el mar y que es utilizada por los grupos armados para el transporte y comercio de droga, equipo de intendencia, armas, etc.

Esta descripción somera sobre la situación del Urabá Antioqueño puede ser terminada con un párrafo de María Teresa Uribe de Hincapié (1992), que condensa las principales aristas de la región:

Urabá no empieza ni termina con el banano, no fue un territorio vacío sobre el cual la racionalidad económica empresarial escribió su lógica; por el contrario, se trató de un territorio vasto tempranamente apropiado, diversamente poblado y estratégicamente situado, en el que se insertó la producción bananera sin lograr disolver o amalgamar las formas tradicionales de vida y de producción económica. (Hincapié, 1992, p. 32)

\section{Años ochenta. La memoria sobre la colonización del Urabá Antioqueño}

La preocupación de la Revista Semana por representar la colonización o migración descontrolada como causa de la situación de conflicto en Urabá tiene límite temporal. Según las informaciones analizadas, en los artículos se reseña este factor durante la década de los 80 , y se realiza una reseña histórica que viene desde los años treinta, "cuando los antioqueños comenzaron a buscar la salida a su mar, Urabá se convirtió en una obsesión" (Revista Semana, 1987). 
El mismo proceso de manera más amplia y con una descripción más académica lo hace Ana María Bejarano en 1988 (1988), seguida por Jaime Parsons (1996), Carlos Miguel Ortiz (2007) entre otros. Y aunque el deber ser de la información periodística no es parecerse a la teoría académica, sí debe decirse que en los artículos analizados, la principal causa de la migración que se nombra es la colonización por motivos económicos por parte de ganaderos que escapan de otras regiones, y de antioqueños que buscan sobrevivir por medio del cultivo del banano.

El proceso de migración descrito en los libros académicos no es homogéneo. Viene de diferentes regiones, adornado con distintas razas y credos e intenciones. Parsons (1996) describe tres oleadas de colonización: la primera, motivada por la empresa norteamericana Emery Boston a principios del siglo XX que buscaba la explotación de madera, y que motivó a trabajadores de todo el país para llegar allí. La segunda, en los años 20, con la primera etapa de la construcción de la carretera al mar bajo el mando de la compañía alemana Siemens Bau-Unión. La tercera en los años 60, la descrita por la Revista Semana, que también buscaba la construcción de nuevas carreteras para el comercio.

Ahora bien, la migración y la colonización trajeron consigo los primeros conflictos violentos, debido a la concentración de tierras. Las distintas oleadas trajeron grupos de migración que luchaban por hacerse a una propiedad, y quizá debido a la debilidad del Estado para controlar este proceso, los choques y enfrentamientos entre terratenientes y colonos se daban de manera violenta. El círculo vicioso de este conflicto es descrito por la revista, citando fuentes de primera mano que protagonizaron las oleadas de los años 60 y que en los 80 combatían a los que llegaban.

Ahora resulta que ellos son los colonos. Y nosotros, que llegamos a esta región hace treinta años y comenzamos a tumbar monte ¿qué somos?... Conquistamos estas tierras y no nos vamos a dejar sacar. Nos vamos a hacer romper por lo que nos pertenece. Primero los sacamos nosotros a "ellos"... Pero nosotros no nos vamos a dejar joder. (Revista Semana (a), 1988)
Estos artículos están enmarcados dentro del informe de la Comisión de Estudios sobre la Violencia, de 1987; sus conclusiones anunciaron el desarrollo de otros tipos de violencia, no solo la violencia política o la violencia del narcotráfico, sino una violencia social causada principalmente por las tensiones entre sujetos con ambición de progreso y ascenso social. Sin embargo, existe una representación del campesino ignorante, ebrio y violento en donde también está presente una conexión con el sistema-mundo y la ambivalencia entre capitalismo y comunismo. Lo que hace interesante la fuente es que se puede ver la intención de autodefensa en contra de los elementos que él considera invasores. No es una autodefensa pacífica o por medios legales, es una autodefensa violenta.

Esta migración de los años 60, a la que hace referencia la Revista Semana, es motivada por el banano, lo que expone otro tipo de conflicto: el del obrero-patrón. Es así como, descrito por la revista, empieza un movimiento colonizador caracterizado por ser originado desde múltiples regiones del campesinado colombiano, principalmente antioqueños. "No fueron pocas las familias, principalmente paisas, que vendieron sus casas y se lanzaron a la aventura del "oro verde", ni pocos los aventureros que con mochila al hombro, llegaron dispuestos a tumbar monte..." (Revista Semana (d), 1988)

El desarrollo de la siembra del banano es representado por la revista como de un éxito rotundo; en los artículos poco a poco se describe el desarrollo de la industria a la par con los problemas sociales. "En estas condiciones, en 1963 se hizo la primera siembra de banano y en 1964 se produjo el primer embarque desde Urabá con 7.541 racimos de banano" (Revista Semana (d), 1988).

En los artículos no se hace referencia a la violencia política, ni a condiciones de violencia heredadas de los años 50, y tampoco a los grupos guerrilleros existentes en la zona ya que en cierta medida garantizaba el orden. En las piezas periodísticas de la Revista Semana eran dos los conflictos: colono-terrateniente y obrero-patrón. Cada uno se alimentaba del otro. 
Sería en 1989, cuando la Revista, al caracterizar 10 zonas de violencia en Colombia, haría la conexión entre estos varios tipos de violencia y predecía que Urabá se convertiría en una zona problemática.

... Hasta bien avanzados los años 70, los propietarios bananeros seguían sometiendo a sus jornaleros a las peores condiciones de trabajo. A la sombra de los conflictos laborales que surgieron de esta situación, el EPL primero y años después las FARC, ofrecieron respaldo político y armado a los sindicatos en formación. Las condiciones de trabajo mejoraron en lo referente a la explotación bananera, pero el poder de la guerrilla se siguió sintiendo siempre con más energía, generando situaciones que se tornaron insostenibles para muchos propietarios. La alianza de algunos de estos hacendados con narcotraficantes que comenzaron a invertir en la región a principios de los 80 , dio origen a la formación de grupos paramilitares, que encauzaron su acción contra los dirigentes y militantes políticos y sindicales que ellos identificaban como aliados de la guerrilla (Revista Semana, 1989).

Es importante reseñar aquí, que según la construcción llevada a cabo por la Revista Semana, el conflicto parece darse a la inversa que en otros territorios de Colombia. Mientras que, la guerra en Colombia se centró en el enfoque de un enfrentamiento político que degeneró en una violencia social y cultural, en Urabá, el conflicto empieza con un problema social generado por la industria bananera que va a degenerar en una confrontación política, pues los grupos armados que apoyan a los sindicatos de trabajadores tienen una ideología comunista. Es así como la Revista Semana, caracteriza a la región como caldo de cultivo para la entrada de la violencia política, del narcotráfico y de los paramilitares. Es una región en donde se da el conflicto por las tierras, la lucha por lo laboral y el combate entre grupos armados ilegales.

Asimismo, la revista reseña los principales problemas que causaron la situación en Urabá. Uno de ellos es la poca presencia del Estado que lo relaciona con las malas condiciones de vida.
En Urabá hay una cama hospitalaria por cada 2.300 habitantes; un médico por cada 7.500 habitantes; el 153 por mil de los nacidos vivos mueren al poco tiempo; la mortalidad es del 10.4 por mil, lo que significa un 25 por ciento más que el promedio del departamento de Antioquia; sólo el 31 por ciento de las viviendas en el área urbana tienen servicio de agua pero no pura... (Revista Semana, 1984)

A este panorama se le suma también una referencia al conflicto por la tierra y otra a la migración debido a la bonanza bananera. Los enfrentamientos tienen como principal característica la masacre. El juez primero del Circuito de Turbo, Rodrigo Uribe, explica esta situación diciendo que: "los invasores luchan por su tierra y los propietarios defienden la propiedad" (Revista Semana, 1984).

Pero como si fuera poco, el artículo de la Revista Semana hace alusión a un problema más, el de la descomposición social y la delincuencia que ha sido la causa prima de las dificultades: pro blemas por la concentración de la tierra, ausencia estatal y delincuencia, factores del conflicto en Urabá que se superponen y se alimentan uno del otro. La Revista Semana parece ejemplificar las consecuencias de este entrecruzamiento de factores en la Matanza de Punta de Piedra, narrada así:

Un hecho que ilustra este grave problema se remonta al 14 de abril, cuando cerca de la media noche, después de que amainó una tempestad que azotaba el mar, $120 \mathrm{fa}$ milias de Punta de Piedra se vieron enfrentadas al horror de una matanza. "Llegaron vestidos como policías con sombreros y dijeron: que salgan las mujeres que tengan niños y fueron disparando", le dijo a un periodista de El Mundo, la campesina Clariben Casarubio... (Revista Semana, 1984)

Así las cosas, la representación sobre Urabá que ayudará a construir memoria hablará de una zona de colonización a causa del banano que desembocaría en conflictos por tierras y tensiones entre el obrero y el patrón, acuciado por la entrada de las guerrillas que le dieron un tinte más político al conflicto y beneficiarían la respuesta de 
los grandes colonos y terratenientes en el uso de grupos de autodefensa para proteger sus tierras, todo esto enmarcado en una débil presencia del Estado.

Asimismo, la representación del factor colonizador y migratorio, que fue fuerte en los años 80 , se irá perdiendo en los años 90, hasta desaparecer casi por completo a mediados de esta década. Los otros factores como la relación entre Estado y sociedad y la dinámica de los grupos armados ilegales, también descritos en los artículos de los años 80, abarcarán más párrafos, hasta que en los 90, la información tendrá un eje central: la representación de los combates y enfrentamientos.

\section{La memoria del conflicto de Urabá desde las relaciones sociedad y Estado}

La representación de las relaciones entre Estado y sociedad en el Urabá Antioqueño es descrita por la revista Semana como un "tire y afloje" entre una presencia real legislativa y oficial, por medio de leyes, comisiones y decretos de cada uno de los gobiernos, y una ausencia en el cumplimiento de estas y la representación política de los verdaderos intereses de la población.

La revista empieza con la mención de una comisión para buscar la paz, y trae como "adelantos" algunas de las políticas implantadas en el gobierno Betancur (1982-1986), sobre todo para mejorar la calidad de vida. (Revista Semana) Pero, estas políticas de mejoramiento eran representadas por la revista como respuestas a corto plazo que no solucionaban el problema, pues la comunidad se había "politizado" debido a los conflictos obreropatronales y a la entrada de la guerrilla, que hacían insuficientes las soluciones del gobierno. (Revista Semana, 1987)

Llegó el gobierno de Barco (1986-1990) y la Revista Semana reseña que Urabá volvió a quedar relegada de las políticas gubernamentales hasta que la violencia recrudeció y se volvió tan visible que se tomaron medidas urgentes. (Revista Semana, 1987). Mientras el gobierno estaba en este ir y venir para emitir políticas que ayudaran a solucionar el conflicto, la Revista Semana describía la situación desde los protagonistas de los conflictos: los propietarios y los campesinos. Los primeros veían la presencia del Estado como un ente inútil totalmente obsoleto a las acciones armadas de la guerrilla.

Cuando hablan, después de asegurarse de que lo están haciendo off the record, los bananeros afirman que el Estado nunca se preocupó por la zona de Urabá, que los empleados bananeros están tan bien pagos como los petroleros o las portuarios, que los pliegos de peticiones se negocian a punta de amenazas, que los administradores no pueden despedir a un trabajador porque su vida se pone en peligro, que las afiliaciones a los sindicatos se hacen a pistolazo limpio y que los inspectores de trabajo o los jueces de la región no pueden actuar porque las metralletas de las FARC y del EPL, no los deja. (Revista Semana (d), 1988)

La guerrilla es vistas como un problema, y entonces nace la sed por defenderse. El círculo vicioso de la violencia colombiana tiene aquí uno de sus ciclos. Los bananeros están dispuestos a responder, a tomar la justicia por sus manos, a reemplazar al Estado en el ejercicio de la violencia. "Urabá está perdido, señor periodista. Y el país lo está dejando perder. Pero ya ha aparecido gente que se cansó de todo esto y está dispuesta a responder" (Revista Semana (d), 1988).

Llegaría el gobierno de César Gaviria (1990 1994) y el Plan Urabá, representado por la revista como una política que se iba a aplicar en una región donde el proselitismo político se hace de manera violenta: "política a bala" titula el artículo. La Revista afirma que las cifras de violencia comienzan a ceder. El conjunto de propuestas se basan en la mejora de las condiciones de vida de los pobladores de Urabá, pero para cumplirse debían ejecutarse bajo un contexto de estabilidad política. Y eso era algo inexistente en la región. La Revista Semana describe la situación como un enfrentamiento entre el Partido Comunista Colombiano y la Unión Patriótica donde cado uno ejecuta actos violentos a través de sus ba- 
ses armadas, el EPL y las FARC, respectivamente, (Revista Semana, 1994)

He aquí otra arista del conflicto. La disputa política de la región por medios violentos, pero con vistas a crear estabilidad para la ejecución del Plan Urabá. La revista anuncia que los representantes de los distintos grupos se reúnen para acordar una tregua. Entre ellos están el Partido Comunista, la Unión Patriótica, los comandos armados populares. La revista reseña la visita del presidente César Gaviria a la región, catalogada como "tierra de nadie" (Revista Semana, 1993). Al final se logra un acuerdo, pero la paz es endeble, y para la llegada del gobierno de Ernesto Samper (1994-1998) la situación sigue igual. La representación construida por la Revista Semana es dramática, y da lugar para afirmar que las propuestas de solución no han servido. El plan de Samper es el de fortalecer la presencia del Estado en el ámbito de su organización y ejecución de las leyes, en lo que Semana bautiza como "la tierra del olvido". ¿Sirvieron de algo las políticas? Al parecer no. A final del mes de octubre de 1995, la Revista Semana reseña una matanza de 26 obreros y sus familias (Revista Semana (a), 1995).

Según la construcción de la Revista Semana, la región de Urabá, se convierte en una zona tórrida, oscura, en donde todos los intentos de solución han fracasado. Para el período de Andrés Pastrana (1998-2002) los artículos que tratan el tema de las relaciones sociedad-Estado en Urabá se silencian. Sólo se habla del proceso de paz e incluso salen a relucir ejemplos particulares para afirmar que la paz negociada sí es una opción viable. Es el caso de un artículo del 2001, que narra el proceso de reinserción del EPL, Esperanza, Paz y Libertad, y cómo después de 10 años parece ser un éxito. (Revista Semana, 2001).

Es así como la Revista Semana describe la relación del Estado con la sociedad en Urabá. El primero es visto como obsoleto, inútil y ausente; mientras que la segunda es vista como falta de representatividad política, llena de carencias cuya única solución es luchar de manera violenta. No existen reminiscencias a la cultura de esta sociedad, solo existen referencias al olvido y a que son tierra de nadie.

\section{Finales de los ochenta y noventa; comienzos del segundo milenio. La memoria del conflicto de Urabá desde la desde la dinámica de la guerra}

La Revista Semana siguió con atención las distintas dinámicas que se llevaron a cabo entre los grupos armados ilegales en la zona. La representación de esta situación se centró en las luchas obrero-patronales que dieron lugar a sindicatos que más tarde fueron apoyados por los grupos guerrilleros. Asimismo, se habló de que los terratenientes de la zona se unieron con narcotraficantes y formaron las autodefensas para hacer frente a las arremetidas de las guerrillas.

Pero, para finales de los años ochenta en adelante, la revista Semana entra en la lógica de mostrar el conflicto desde una "guerra de posiciones" concepto explicado por Fernán González, Ingrid Bolívar y Teófilo Vásquez (González, Bolívar y Vásquez, 2002, p.121) como la estrategia armada de los grupos ilegales parecida a una situación especular de simetría y espejos miméticos, en donde se reseñan las acciones violentas de uno y otro bando en la región de Urabá. Como vimos anteriormente, para 1987, se habla de que la situación socio-política de Urabá era un "caldo de cultivo" para la generación de guerrillas; según la representación de la Revista Semana, la aparición de estos grupos era esperable y predecible, debido al contexto del país y a que las condiciones estaban dadas. "... Y la cosa fue la guerrilla, que aterrizó en el sitio perfecto: la contradicción social entre obreros agroindustriales recién salidos de peones, y empresarios con comportamientos feudales heredados de su función de colonizadores" (Revista Semana, 1987).

En los años 80, para la revista Semana es de vital importancia reseñar el origen histórico de los grupos armados ilegales en la región, y hablar de ellos como organizaciones que sustentaron las luchas sindicales en Urabá en un contexto delincuencial, que según la revista ha caracterizado a la región como una zona aparte del territorio 
colombiano. Aquí se empiezan a reseñar las masacres de grupos "desconocidos" que no se pueden definir como guerrilleros expresamente, pero que sí son adscritos a grupos de izquierda. El asunto es que los grupos armados ilegales empiezan a disputarse la zona de manera violenta para adueñarse de los territorios y las filiaciones políticas. La revista describe a los grupos armados ilegales desde la cantidad tanto de sus hombres como de la cobertura de las zonas de influencia, a cuya presencia se le suma la del ejército con operativos estratégicos.

La Revista Semana nombra estos enfrentamientos como una "guerra sucia", por las víctimas civiles que dejan los combates entre estos grupos. A su vez, los propietarios de tierras son visibilizados como personas que hablan de defenderse con las armas o con cualquier medio necesario y enmarcan la lucha dentro del contexto internacional de la Guerra Fría.

La revolución, el poder popular, el fin de la propiedad privada, la socialización de la tierra y el comunismo son expresiones típicamente familiares para los empresarios del banano y los ganaderos de la zona. Para ellos, la famosa dictadura del proletariado proclamada por Marx es una realidad cotidiana (Revista Semana (d), 1988).

Estas posiciones radicales se extienden por todos los estratos de la población, al mismo tiempo parece haber un sesgo hacia los propietarios. La Revista Semana afirma que los pobladores están convencidos de que para salvar a Urabá se requiere una cruzada anticomunista, en donde "el derramamiento de sangre" será algo común y esperado ante las condiciones del Estado para no asumir la defensa de los intereses privados de la "gente de bien". ¿Qué se puede esperar de este panorama? La entrada de los paramilitares no se hace esperar. "Esta realidad es la que está llevando a los propietarios medios y ricos de Urabá a la conclusión de que la erradicación de la violencia les corresponde a ellos. El resultado de este tipo de "operaciones de limpieza" no puede ser otro que el de la generalización de la guerra" (Revista Semana (d), 1988).

En los años 90 y hasta el 2002, la revista
Semana centra su información sobre la dinámica del conflicto, reseñando las masacres, combates y luchas entre guerrilleros, ejército y paramilitares. Se puede decir aquí que la violencia en Urabá se convierte solamente en las acciones armadas de los actores ilegales con un objetivo territorial que muchas veces se ve desdibujado en, como lo describe la revista, una guerra de posiciones.

Esta representación se caracteriza, primero, como un enfrentamiento entre las mismas guerrillas, que han perdido sus ideales de proteger al menos favorecido. Segundo, como un enfrentamiento entre la guerrilla y la sociedad civil. Tercero, como pugna entre la guerrilla y los desmovilizados de otros grupos guerrilleros. Cuarto, como una lucha entre guerrilleros y paramilitares. Quinto como una confrontación por el territorio. (Revista Semana (a), 1996)

Para la Revista Semana la principal característica de esta guerra, además de los enfrentamientos violentos, son las masacres en contra de la población. La revista cita al investigador de la Universidad Nacional, Alejandro Reyes, "Esta es una guerra de mensajes, donde cada masacre es un mensaje al adversario. Estamos frente a una disputa de posiciones en términos de estrategia militar". Revista Semana (a), 1996). Los artículos se convierten en "caja de resonancia" de las masacres; se utilizan narraciones descriptivas lejos de la objetividad periodística, con altas dosis de dramatismo y recursos literarios que transgreden la crónica y presionan los géneros periodísticos a límites difíciles de definir.

Aparecieron como fantasmas en la calle principal del caserío. Era la 1:30 de la tarde del 4 de mayo. El calor era sofocante. Los cuatro enormes camiones, atestados de hombres armados con fusiles, recorrieron las precarias calles. Estaban desoladas. La mayoría de los 2.500 habitantes de Puerto Alvira, Meta, se protegía del clima en la fresca sombra de sus casas. Por eso pocos se dieron cuenta de la llegada de quienes minutos después serían sus verdugos. Cerca de 200 hombres descendieron de los automotores y de inmediato asumieron el control. Vestían uniformes de camuflaje identifi- 
cados con un emblema de las Autodefensas Unidas de Colombia (AUC). (Revista Semana, (a), 1998)

Por otro lado, el ejército es representado como débil, como un grupo que desvela la imposibilidad del Estado para hacer frente a la situación. Este grupo se representa a sí mismo como efectivo, en la descripción de las ofensivas contrainsurgentes sus fuentes dicen causar centenares de muertos en el otro bando. Esta visión optimista es fácilmente aplacada por la revista, para quienes la situación dista mucho de ser resuelta.

En estos años se da la inserción de la Revista a reseñar la dinámica del acontecimiento bélico, se representa a la guerrilla como un actor que ha convencido a los campesinos y se ha convertido en un problema; a las autodefensas como seres oscuros, terribles y desconocidos; y al ejército como un grupo endeble que pretende emitir una imagen exitosa pero que según la revista ha fracasado en el intento de controlar el orden público.

\section{Conclusión: Entonces ¿qué memoria se construye del conflicto en Urabá?}

La construcción de la memoria en los artículos de la Revista Semana muestra dos fases diferentes. En los ochenta, se hace referencia a los enfrentamientos de las migraciones y la colonización campesina, se muestran las condiciones sociales que influyen en el recrudecimiento del conflicto y se hace alusión a un contexto histórico que se remite a los años 60. A principios de los noventa, la representación de la memoria del conflicto se transforma, se van perdiendo las alusiones a las condiciones sociales que causan la guerra en esa región y se enfatiza en las relaciones de Estado con los poderes locales, en pocos artículos aún se hace referencia a los enfrentamientos entre colonos y migrantes. A finalizar esta década, la revista se vuelca a la reseña del hecho-acontecimiento bélico, y se visibiliza el conflicto como una disputa por el territorio en el que varios grupos se enfrentan por legitimar su poder, pero la única mención que se hace al valor estratégico es el narcotráfico.

Por lo tanto, es una construcción de memoria en donde prima lo geográfico sin conexión con lo político, y en donde como se verá, los sujetos sociales se visibilizan de dos formas, como víctimas o como victimarios, nunca como parte de un proceso histórico de transformación social.

En el 2001 Carlos Andrés Ríos, ganador del premio a mejor trabajo de Ciencias Sociales otorgado por El Espectador, critica en su trabajo el estereotipo violento creado en torno a la región de Urabá. Estereotipo que se caracteriza de dos maneras como una falta de conocimiento por la identidad cultural de la región, tanto de los colonos, como de los indígenas, los desplazados y los pobladores urbanos, y por otro lado, el reduccionismo de entender la región solo a partir de los aspectos bélicos y de conflicto.

Evidentemente, la construcción de la memoria hecha por la revista Semana se relaciona con las conclusiones de Ríos. En ningún momento los artículos hacen referencia a aspectos distintos a la guerra o a las confrontaciones; las voces de los sujetos sociales se utilizan para visualizar la problemática, y nunca como sujetos que están dentro de un proceso en el que intervienen otros aspectos y no solo los del conflicto armado.

En la figura 2 se puede observar una mejor explicación sobre los tres aspectos desde los que se construye memoria a partir de la Revista Semana sobre Urabá. Número uno, Urabá como zona de colonización en la que el territorio cobra vital importancia y se producen enfrentamientos entre colonos y terratenientes por la tenencia de la tierra. El banano es el eje de estas migraciones. En la revista es muy fuerte esta explicación, sobre todo en la década de los ochenta, es tenue en los noventa, y a partir de esta década desaparece. Número dos, una construcción de la memoria en la relación de Urabá con el Estado, con respecto a políticas y programas comienza a mediados de los años ochenta y se vuelve muy fuerte a partir de los noventa. Número tres, las acciones bélicas entre grupos armados legales e ilegales empiezan a reseñarse desde los años ochenta hasta ser muy fuertes, e incluso la única referencia de la zona, en los noventa y el dos mil. Cabe decir que estas 
Figura 2: $\quad$ Construcción de Memoria de Urabá

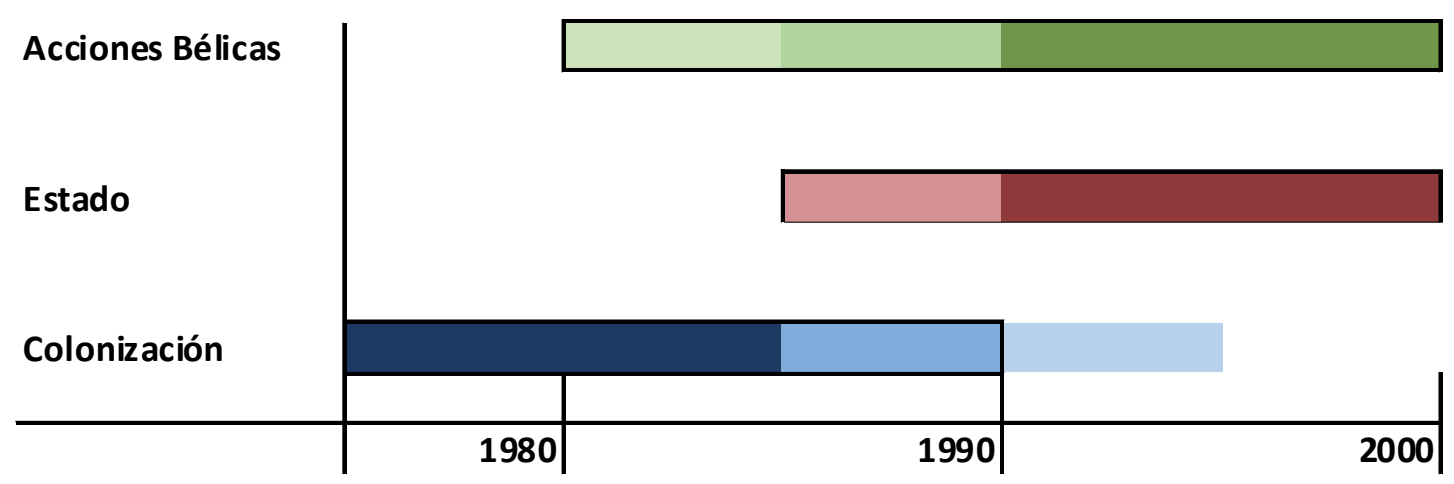

Figura 2.

construcciones se contraponen en los artículos de las revistas, en uno mismo se puede hacer incluso referencia a todos ellos, dependiendo, como es lógico, de los años.

Ahora bien, quiero hacer referencia a que no solo la prensa hace estos reduccionismos. Cuando se observa la tradición historiográfica sobre Urabá o sobre el conflicto colombiano se pueden observar las mismas tendencias. Ríos denuncia este aspecto en su trabajo basándose en las investigaciones de Carlos Miguel Ortiz sobre Urabá. (Ríos, 2001)

Por eso, se puede realizar un cruce somero entre lo reseñado en este texto con las teorías de la historiografía sobre el conflicto en Colombia, por los menos con las principales, y así poder abrir un debate o inspirar trabajos futuros. ¿Qué teorías se pueden visualizar en la construcción de memoria que hace la revista Semana del conflicto en Urabá?

Primero, Daniel Pecaut (1987) y su teoría de crisis del Estado como factor del conflicto en Colombia. Pero este proceso se vio más representado en la mentalidad de los pobladores quienes querían hacer justicia por sus propias manos. Urabá refleja la desarticulación de la sociedad en el estado mismo, manifestado en el clientelismo, en la inexistencia del monopolio de la coerción, y en una ambivalencia entre los poderes locales contra los poderes centrales.

Otra de las teorías que se relacionan con la representación de Semana sobre el conflicto en el Urabá antioqueño es la que plantean autores como Fernán González, Ingrid Bolívar y Teófilo Vásquez (González, Bolívar, Vásquez, 202, p. 122), con respecto a la construcción del Estado; los teóricos aseveran que los intentos de crear un Estado moderno hizo permanente el problema agrario del campesinado colombiano (problema que viene engendrado desde la Colonia, según los teóricos) debido a que las instituciones oficiales nunca expresaron una estructura que representara la totalidad de la sociedad colombiana, lo que hizo que el Estado se diferenciara según la región y el tiempo. Esto se vio en los contextos históricos reseñados como procesos de colonización descontrolada que llevaron a la concentración de tierras.

Asimismo, se vio en la representación del conflicto en Urabá por la revista Semana que el proceso de construcción del Estado está acompañado de la creación y consolidación de diferentes redes de poder local y regional, cuya relación con el primero se daba a través del gamonalismo con lógicas clientelistas. En esta relación entre poderes locales y centrales, se da el proceso de modernización del país patrocinado por el Estado, pero limitado por la acción de esas redes de poder regionales. Pero es en las zonas donde no existen ni redes locales, ni Estado donde se da la "estructura de las oportunidades" en los cuales los pobladores, por medio de las armas 
construyen órdenes políticos alternativos. Aquí, el Estado no ostenta el monopolio de la fuerza, y el vacío es ocupado por los grupos armados que intentan crear cierto orden de convivencia social. Pero estos grupos se desplazan geográficamente, ya sea por voluntad propia debido a decisiones internas o a factores bélicos externos como los ataques de los años sesenta contra Marquetalia que causó el desplazamiento del grupo hacia otras regiones. Al trasladarse, ocupan otro territorio y amenazan el poder de las redes locales, estas últimas, acosan al Estado por abandono y crean su propio grupo para defender sus intereses: las autodefensas, que entrarán en una dinámica de resguardo del orden político de las élites, reemplazando en esta función al Estado e incluso bajo su amparo.

Los grupos armados entran en una dinámica de "juego de espejos" lo que en la Revista se llama "guerra de posiciones" que es un proceso en el cual una acción bélica es respondida por otra de igual o mayor envergadura y así sucesivamente hasta crear una escalada casi interminable de violencia entre uno y otro bando. Debe decirse que la entrada del narcotráfico no se ve muy bien, pero sí la disputa por el aspecto geográfico. Mientras tanto, el Estado sigue un proceso de construcción, tratando de insertarse en las dinámicas de las regiones, creando entonces presencia diferenciada del mismo, lo que vimos como los distintos planes ejecutados por los presidentes.

Otro enfoque que pudo verse en la representación del conflicto en Urabá por la Revista Semana es el que ofrece Fajardo (1977); el autor trabaja el Tolima entre 1930 y 1970 y afirma que la violencia tuvo que ver con la concentración de la tierra, la penetración de diferentes actores tales como colonos, arrendatarios, peones y agricultores, lo que la revista explica como contexto histórico.

La Revista Semana y la historiografía parecen haber construido la memoria de un lugar, Urabá, como una zona tórrida, difícil y ejemplo de un lugar en la que se dan todas las condiciones para un conflicto, atrasada hasta el punto de lo feudal.

\section{Bibliografía}

Bejarano, A. M. (1988). La violencia regional y sus protagonistas: el caso de Urabá. Revista Análisis Político.

Bucheli Gómez, M. (2005). Bananas and business the United Fruit Company in Colombia, 1899-2000. New York: New York University Press.

Comercio, C. D. (2005) Informe Económico 2005. Recuperado el 18 de marzo de 2008, de Cámara de Comercio de Urabá: www.ccuraba.org.co/web/files/ informeSocioeconómico2005.pdf

Fajardo, D. (1977). La violencia y las estructuras agrarias en tres municipios cafeteros del Tolima: 1936-1970. En J. A. Bejaran, E D. Fajardo, El Agro en el desarrollo histórico colombiano. Bogotá.: Punta de Lanza.

García, C. I. (1996). Urabá: Región, actores y conflicto 19601990. Bogotá: CEREC.

González, Bolívar, Vásquez. (2002). Violencia política en Colombia. De la Nación fragmentada a la construcción del Estado. Bogotá: CINEP.

Hincapié, M. T. (1992). Urabá: ¿Región o territorio? Medellín: INER; CORPOURABA.

LeGoff, J. (1992). El orden de la memoria. El Tiempo como imaginario. Madrid: Paidós Básica.

Ortiz, C. M. (1992). Urabá, pulsiones de vida y desafíos de muerte. Bogotá: La Carreta Editores.

Parsons, J. (1996). Urabá, salida de Antioquia al mar. Geografía e historia de su colonización. Bogotá: Ancora.

Pecaut, D. (1987). Orden y violencia: Colombia 1930- 1953. Bogotá: CEREC.

Ríos, C. A. (2001). Identidad y religión en la colonización en el Urabá antioqueño. Bogotá: El Espectador Ascún.

Rozo Sánchez, A. M. (1981). La Relación entre el gobierno y la United Fruit Company 1924-1930 el colono y el problema de la tierra en el Departamento del Magdalena. Bogotá: Universidad Javeriana.

Vásquez, M. L. (2004). La prensa como fuente histórica: la percepción del modelo estadounidense. IV Simposio de Historia Actual (págs. 435-446). Logroño. Instituto de Estudios Riojanos. 
Publicaciones Periódicas Analizadas (Revistas):

Revista Semana. (1983, 26 de septiembre). El Regreso de la Violencia. Abandono de tierras, éxodo de campesinos, asesinatos, extorsiones, secuestros y enfrentamiento entre la guerrilla y el ejército son el pan de cada día en el Magdalena Medio. Revista Semana, 69.

Revista Semana, (1984, 18 de junio). El nuevo Magdalena Medio. Invasores, paramilitares y guerrilla repiten en el golfo de Urabá la historia del Magdalena Medio. Revista Semana, 107.

Revista Semana (a). (1986, 18 de junio de marzo). El nuevo magdalena medio. Invasores, paramilitares y guerrilla repiten en el golfo de Urabá la historia del magdalena medio. Revista Semana, 107

Revista Semana (b). (1986, 3 de marzo). Del Cauca a Bucaramanga, pasando por el Magdalena medio, vuelven a hablar los fusiles. Revista Semana, 196.

Revista Semana (c). (1986, $1^{\circ}$ de junio). Guerra total y guerra sucia. Mientras aumenta el número de muertos, la opinión pública sigue perdiendo la guerra de la desinformación. Revista Semana, 188

Revista Semana. (1987, 18 de Mayo). Banana Republic. Después de que lo hicieran la guerrilla, los paramilitares, el narcotráfico y la delincuencia, el estado colombiano decide meter la mano en Urabá. Revista Semana, 259

Revista Semana (a). (1988, 18 de julio). La masacre de Urabá. Tras el asesinato de 20 trabajadores en currulao, podía existir un plan para perturbar la elección popular de alcaldes. Revista Semana. 320

Revista Semana (b). (1988, 18 de julio). 30 años no es nada. Nueva o vieja, la violencia política sigue cobrando víctimas. Revista Semana, 320.

Revista Semana (c). (1988, 11 de julio). Las balas perdidas. Éxitos militares, medio centenar de muertos y denuncias de abusos contra la población civil, el resultado de los combates ejército guerrilla en Urabá. Revista Semana, 319.

Revista Semana (d). (1988, 13 de junio). La contrarrevolución en Urabá. Surge en la región una nueva derecha, organizada y violenta, decidida a barrer el comunismo a cualquier costo. Revista Semana, 315.
Revista Semana (e). (1988, 30 de mayo). El dossier de Urabá. Explosivas revelaciones en documento confidencial del DAS, establecen vinculaciones de algunos elementos de las fuerzas armadas con las matanzas de Urabá. Revista Semana, 313.

Revista Semana (f). (1988, 10 de octubre). El prontuario. Después de haber estado vinculado a los casos Lara, Cano y el Procurador, Pablo Escobar es sindicado de ser el cerebro de las masacres de Urabá. Revista Semana, 332.

Revista Semana. (1989, 17 de abril). El atlas de la violencia Semana zonifica a Colombia en diez regiones críticas de violencia, y analiza en cada una de ellas la historia y las características del conflicto. Revista Semana, 359.

Revista Semana. (1991, 29 de abril). Las otras batallas de Urabá. Revista Semana, 465.

Revista Semana. (1992, 25 de mayo). La puja bananera. La salida de Uniban del más grande empresario bananero del país, desata una batalla que puede comprometer el futuro de esa importante compañía. Revista Semana, 521.

Revista Semana. (1993, 27 de diciembre). Política a bala (Urabá). Tras las masacres de la semana pasada en Urabá, queda claro que en las próximas elecciones pesarán más las balas que los votos. Revista Semana, 604.

Revista Semana. (1994, 7 de noviembre). La cascarita. A pesar de los anuncios, por ahora la suerte del banano sigue un camino diferente al de las flores. Revista Semana, 604.

Revista Semana (a). (1995, 23 de octubre). El dialogo ha muerto. La última masacre perpetrada por la guerrilla en Urabá confirma que con su actitud los alzados en armas derechizaron al gobierno y a la opinión y acabaron con las posibilidades de una negociación. Revista Semana, 699.

Revista Semana (b). (1995, 2 de octubre). La tierra del olvido. Con la masacre del martes las FARC escalan una sangrienta ofensiva contra la población civil de Urabá y reactivan una guerra que ya va para dos décadas. Revista Semana, 696.

Revista Semana (a). (1996, 10 de junio). La guerra del golfo. Guerrilla y paramilitares desatan la gran 
guerra en Urabá, mientras el Estado permanece de espectador y la población civil muere en el fuego cruzado. Revista Semana, 732.

Revista Semana (b). (1996, 30 de diciembre). El dossier de Mauss. Las últimas revelaciones parecen indicar que, aparte del ELN, hay vinculaciones del alemán con el tráfico de armas en Urabá, el de drogas desde Córdoba y el secuestro de Camila Michelsen. Revista Semana, 761)

Revista Semana. (1997, 18 de agosto). El rambo de las FARC. Un guerrillero preparado en las academias de la unión soviética y de alemania oriental es el nuevo jefe militar de las FARC en Urabá. Revista Semana, 794.

Revista Semana (a). (1998, 8 de junio). Tierra arrasada. La Masacre de Puerto Alvira demuestra que los 'paras' están dispuestos a todo para sacar a las FARC de sus territorios. Revista Semana, 836.

Revista Semana (b). (1998, 21 de diciembre). Llego la artillería. Con golpes en el sur de Bolívar y el Urabá antioqueño las FARC se ponen al frente en su guerra contra Carlos castaño. Revista Semana, 864.

Revista Semana (a). (1999, 17 de mayo). Guerra de posiciones. Los sucesos de la semana pasada, en los que murieron 19 soldados, demuestran que la guerra en el Urabá antioqueño está lejos de terminar. Revista Semana, 885.
Revista Semana (b). (1999, 19 de abril). Sigue la ofensiva. Con sus éxitos operativos en Urabá, las fuerzas militares comienzan a recoger los primeros resultados de su nueva estrategia. Revista Semana, 881.

Revista Semana. (2000, 20 de noviembre). Con el baño de sangre de Dabeiba y el bloqueo al Putumayo la guerrilla desafía al plan Colombia. El país no ha asimilado que la guerra ha entrado en una nueva fase. Revista Semana, 964.

Revista Semana. (2001, 16 de abril). El milagro de Urabá. Diez años después de desmovilizado el EPL demuestra que la paz negociada no sólo es posible sino que es políticamente rentable. Revista Semana, 985.

Revista Semana (a). (2002, 13 de mayo). Guerra privada. La masacre de bellavista es otro trágico episodio del enfrentamiento entre las FARC y las AUC por el control de las rutas estratégicas, coca y heroína. Revista Semana, 1045.

Revista Semana (b). (2002, 19 de Febrero) Guerra contra la gente. En Colombia dos millones de personas son desplazadas convirtiéndose el cuarto país con mayor índice de desplazamiento en el mundo. Lea el último informe de CODHES sobre el tema, mapas de desplazamiento, reportaje gráfico y opiniones variadas. Revista Semana, 1033. 